Artículo

\title{
Nuevos iniciadores matK para código de barras de la vida en especies del género Dasylirion
}

\author{
Martha Monzerrath Orozco-Sifuentes ${ }^{1}$ \\ Dulce Victoria Mendoza-Rodríguez ${ }^{1}$ \\ Fernando Hernández-Godinez ${ }^{2}$ \\ Octavio Martínez ${ }^{2}$ \\ José Ángel Villarreal-Quintanilla ${ }^{1}$ \\ M. Humberto Reyes-Valdés ${ }^{1 \S}$
}

${ }^{1}$ Programa de Doctorado en Recursos Fitogenéticos para Zonas Áridas-Universidad Autónoma Agraria Antonio Narro. Calzada Antonio Narro 1923, Buenavista, Saltillo, Coahuila, México. CP. 25315. Tel. 844 4110296, ext. 2607. (monze82@yahoo.com.mx; mendozadul@hotmail.com; javillarreal00@ hotmail.com). ${ }^{2}$ Unidad de Genómica Avanzada-CINVESTAV. Carretera Irapuato-León km 9.6, Libramiento norte, Irapuato, Guanajuato, México. CP.36821. (octavio.martinez@ cinvestav.mx; fehernan@ cinvestav.mx).

${ }^{\S}$ Autor para correspondencia: mathgenome@gmail.com

\section{Resumen}

Las especies de Dasylirion se encuentran dentro de las más importantes del desierto chihuahuense en términos ecológicos y económicos. Su uso principal es la elaboración de una bebida alcohólica tradicional llamada sotol. El género comprende 22 especies, no todas aptas para este fin y su identificación es difícil. Herramientas moleculares como el código de barras de la vida facilitan su identificación y generan información genética. Hay iniciadores universales para el gen matK, cuya secuencia es apropiada para código de barras de la vida, que no funcionan para algunas especies de este género. La diferencia de un solo nucleótido puede generar problemas en la amplificación. El objetivo de este trabajo fue diseñar y probar nuevas secuencias iniciadoras del gen matK, que permitan amplificación en las plantas del género Dasylirion. Para el diseño se utilizaron los programas Primer3 Plus, FastPCR y la secuencia completa del gen matK de D. wheeleri. Los nuevos oligonucleótidos fueron probados con las especies D. texanum, D. leiophyllum, D. occidentalis y $D$. palaciosii, con amplificación limpia del gen matK (fragmento aproximado 1000 pb) en cada una de ellas. Estos resultados contrastaron con los obtenidos a partir de los iniciadores universales $m a t K 390 \mathrm{~F}$ y $m a t K 1326 \mathrm{R}$, que generaron bandas secundarias o fallaron en la amplificación. Ya que los nuevos iniciadores amplificaron exitosamente el gen matK en las especies estudiadas de Dasylirion, se consideran de valor para como herramientas para la obtención de código de barras de la vida en sotol. Investigación realizada durante los años 2016 a 2018.

Palabras clave: Dasylirion, identificación, oligonucleótidos, sotol, zonas áridas.

Recibido: mayo de 2019

Aceptado: agosto de 2019 


\section{Introducción}

En México, $40 \%$ del territorio nacional está conformado por zonas áridas y semiáridas. Incluyen una parte considerable del más grande desierto de norteamérica, el desierto chihuahuense, una de las regiones con mayor riqueza de especies en el mundo (Granados-Sánchez, 2011). En él se albergan alrededor de 6000 especies vegetales de tamaños variables y formas complejas, con un alto porcentaje (50\%) de endemismo (Rzedowsky, 1965; Sarukhán et al., 2009).

Desde tiempos antiguos las especies del desierto han sido aprovechadas para el consumo humano, como material de construcción, como barreras naturales, como fibra, como forraje para ganado y recientemente en la obtención de sustancias de interés económico como las gomas, resinas, látex, almidón y metabolitos secundarios dirigidos a aplicaciones médicas (González-Medrano, 2012).

Uno de los géneros con mayor importancia económica, ecológica y cultural en las zonas áridas es Dasylirion (Familia Asparagaceae). Estas plantas son comúnmente llamadas sotoles y de ellas se obtiene una bebida alcohólica tradicional llamada 'sotol', la cual cuenta con protección a la denominación de origen para Chihuahua, Coahuila y Durango (IMPI, 2002). Sin embargo, no todas las especies de este género son aptas para dicho propósito.

Las plantas de sotol forman parte del matorral desértico rosetófilo (MDR) que representa aproximadamente 12\% del área total del desierto chihuahuense (Rzedowski, 1965; GranadosSánchez, 2011). Se caracterizan por poseer tallos cortos y robustos, hojas largas arrosetadas con espinas en los bordes. Presentan un escapo floral de hasta $5 \mathrm{~m}$ de altura y su fruto es una cápsula indehiscente con una semilla.

Como componente ecológico del desierto contribuye al mantenimiento del suelo, mientras que sus hojas y semillas son alimento de aves y roedores (Reyes-Valdés et al., 2012). Sus hojas se utilizan en la elaboración de adornos para fiestas patronales y en tiempos de sequía como forraje para el ganado, mientras que su escapo sirve como material de construcción y en la fabricación de bastones (Encina-Domínguez et al., 2013). Existe evidencia de su uso como alimento por grupos indígenas (Short et al., 2015), quienes cocinaban el tallo en pozos con piedras calientes y del centro ya cocido obtenían una harina para preparar panecillos o tortas.

En la actualidad se reconocen 22 especies del género Dasylirion distribuidas en zonas montañosas áridas y semiáridas de Norteamérica, desde el sur de Estados Unidos de América hasta Oaxaca en México (Bogler, 1998; The Plant List, 2013; Tropicos, 2018). El género ha sido clasificado dentro de diferentes familias botánicas, entre ellas Liliaceae, Agavaceae, Nolinaceae, Ruscaceae y actualmente en la familia Asparagaceae (Villaseñor, 2016; Tropicos, 2018).

Las plantas de este género presentan rasgos distintivos; uno de ellos es la forma de las hojas, con variaciones en cuanto a longitud y amplitud, la orientación de las espinas en el margen, la presencia o ausencia de cera epicuticular, así como la forma de su superficie foliar (Bogler, 1994). El reconocimiento taxonómico implica un adecuando conocimiento de los rasgos particulares entre una especie y otra. La iniciativa de secuenciar un fragmento corto de DNA que sirva como identificador universal, mejor conocida como código de barras de la vida, es una alternativa en la resolución de la variación existente entre las especies de Dasylirion. 
La búsqueda se ha centrado en genes de cloroplasto (matK, $r b c L, r p o \mathrm{C} 1 \operatorname{trnH}$ - $p s b A$, entre otros) pero muy pocos son efectivos de manera individual, ya que no presentan suficiente variación (Jing et al., 2011). Se propuso usar como código de barras de la vida para angiospermas la combinación de las secuencias de matK y rbcL (CBOL, 2009). Las secuencias anteriores han sido utilizadas en la caracterización de algunas especies del género Dasylirion, incluyendo $D$. serratifolium, $D$. wheeleri, D. miquihuanense y recientemente $D$. micropterum, ésta última recientemente descrita en los límites de los estados de Coahuila y Nuevo León.

Las secuencias de matK y $r b c L$ para dichas especies se encuentran registradas en el GenBank del NCBI (Hebert et al., 2003; Reyes-Valdés et al., 2016; Villarreal-Quintanilla et al., 2016). El gen de la maturasa $\mathrm{K}$ ( $m a t K)$ propuesto por el Consortium for the Barcode of Life como gen de identificación en conjunto con el gen $r b c L$, subunidad grande de la ribulosa-1,5-bifosfato carboxilasa, han dado resultados favorables para un gran número de plantas (CBOL, 2009); sin embargo, la universalidad de dichos marcadores se ha visto obstaculizada por factores como la variación morfológica, geográfica, la evolución reticular y la falta de variación de esas secuencias en muchas especies de plantas, por lo cual algunos investigadores consideran que los marcadores de código de barras de la vida pueden no funcionar para todos los géneros de plantas terrestres (Roy et al., 2010), lo que conlleva por ejemplo a proponer nuevas regiones altamente variables dentro del gen $\operatorname{matK}(600 \mathrm{a} 800 \mathrm{pb})$ con sitios de alineación altamente conservados, evitando la repetición de mononucleótidos (Jing et al., 2011).

Algunos investigadores se han dado a la tarea de diseñar iniciadores específicos, dentro de regiones conservadas del gen $m a t K$, que sean de utilidad en la identificación de diferentes grupos taxonómicos. Ciertos iniciadores han sido diseñados de manera específica para Equisetum (Hausner et al., 2006), para el orden de las Cariófilas (Cuénoud et al., 2002), entre otros. Jing et al. (2011) proponen los iniciadores $m a t K 472 \mathrm{~F}$ y $m a t K 1248 \mathrm{R}$ como alternativas en la resolución parcial de los inconvenientes presentados al utilizar el gen matK como código de barras de la vida. Los iniciadores fueron probados con éxito en 58 especies de 47 familias de plantas angiospermas.

Algunos de estos_iniciadores que han sido diseñados para ciertos grupos taxonómicos, han sido de utilidad en la identificación de otros. Sin embargo, no se descarta que se presentan inconvenientes.

El objetivo de esta investigación fue diseñar iniciadores mat $K$ efectivos en la identificación de especies del género Dasylirion, cuya amplificación con los iniciadores universales matK 390F (5'CGA TCT ATT CAT TCA ATA TTT C-3') y matK 1 326R (5'-TCT AGC ACA CGA AAG TCG AAG T-3') (Cuénoud et al., 2002) generaron bandas de tipo secundario y secuencias de mala calidad.

\section{Materiales y métodos}

\section{Amplificación con iniciadores matK 390F y matK $1326 \mathrm{R}$}

Los iniciadores matK 390F y matK $1326 \mathrm{R}$ propuestos por Cuénoud et al. (2002), fueron útiles en la amplificación del gen matK en las especies de D. micropterum KU535883.1 y D. miquihuanense KU535884.1, registradas actualmente en el GenBank del NCBI. Sin embargo, no funcionaron para las especies de D. texanum, D. leiophyllum, D. occidentalis y D. palaciosii. Para determinar la falla en el proceso de amplificación, se realizaron modificaciones a la técnica de PCR. 
En primer lugar, se aseguraron las condiciones de asepsia y se renovaron los reactivos para PCR. Posteriormente se realizó un gradiente de 12 temperaturas tomando como referencia las temperaturas de alineación (Tm) propuestas por el proveedor $\left(53.4{ }^{\circ} \mathrm{C} \operatorname{matK} 390 \mathrm{~F}\right.$ y $60.8{ }^{\circ} \mathrm{C}$ matK 1326R). Con estas condiciones se obtuvo respuesta de amplificación a $52.2^{\circ} \mathrm{C}$. Posteriormente se verificó la calidad del DNA, con base en la relación absorbancia 260/280 con valores entre 1.6 a 1.8 , se modificaron las concentraciones de los iniciadores (derecho e izquierdo), se aumentaron las concentraciones de dNTPs, y se probó la inclusión de Buffer con $\mathrm{Mg}$ y sin $\mathrm{Mg}$.

Estas modificaciones dieron resultados negativos o con algunas bandas intermitentes amplificadas para las especies de D. texanum, D. palaciosii y D. leyophyllum. Solo dieron resultados positivos en D. occidentalis y D. micropterum, esta última utilizada como control (+). Sin embargo, al momento de la secuenciación, los productos de amplificación no resultaron apropiados para el procesamiento.

\section{Análisis de complementariedad con iniciadores matK 390F y matK 1326R}

Se realizó un análisis de complementariedad por medio de BLASTn (NCBI) para los iniciadores matK 390F y matK 1 326R. Los oligonucleótidos se alinearon con las secuencias completas del gen $m a t K$ de $D$. wheeleri (HM640588.1) y D. serratifolium (HM640587.1) únicos registros de genes completos para el género Dasylirion en el GenBank (Kim y Kim, 2010). En particular se sometió a prueba la existencia de coincidencia entre las bases nucleotídicas de los iniciadores y las secuencias mencionadas.

\section{Diseño de iniciadores matK}

Se diseñaron iniciadores matK para el género Dasylirion, con ayuda de los programas Primer3Plus (Rozen y Skaletsky, 2000), FastPCR Professional 6.6 (Kalendar et al., 2017) y con base en la secuencia completa del gen matK de la especie D. wheeleri (HM640588.1) registrada en el Gen Bank (Kim y Kim, 2010). De los iniciadores generados se eligieron aquellos que presentaron el mayor porcentaje de complejidad lingüística y mayor eficiencia en PCR in silico evaluados en el programa FastPCR.

Cuando una secuencia de nucleótidos se escribe como un texto, es posible medir la repetitividad de las letras. Con esto se obtiene una medida conocida como complejidad lingüística, bajo este criterio, las secuencias de DNA menos repetitivas tendrán una mayor complejidad y viceversa. Adicionalmente se buscó que la zona amplificada coincidiera con la mayor parte de la región intercalada entre los dos iniciadores universales (Jing et al., 2011).

\section{Colecta de material vegetal}

Se recolectaron hojas sanas y jóvenes de por lo menos seis ejemplares por especie. Entre ellas $D$. texanum, en Allende, Coahuila (28 $8^{\circ} 10^{\prime} 12.6^{\prime \prime}$ latitud norte, $101^{\circ} 00^{\prime} 49.6^{\prime \prime}$ longitud oeste, 520 msnm), D. leiophyllum en Sierra Mojada, Coahuila (27 $16^{\circ} 19.3$ " latitud norte, $103^{\circ} 38^{\prime} 2.9^{\prime \prime}$ longitud oeste, 1344 msnm), D. occidentalis en San Juan de Hornillos, Zacatecas (23 03' 645" latitud norte, $103^{\circ} 06^{\prime} 286^{\prime \prime}$ longitud oeste, $2280 \mathrm{msnm}$ ) y D. palaciosii en Guadalcazar, San Luis

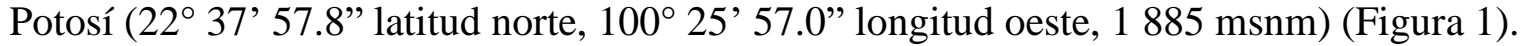


Cada ejemplar fue etiquetado, georreferenciado y las muestras de hojas fueron colocadas en bolsas de papel para su transporte. Previo a la extracción de DNA, el material fue lavado con una solución de hipoclorito al $1 \%$ y posteriormente con etanol al $70 \%$ por un minuto. Al final se quitó el exceso con agua estéril y se dejó secar sobre toallas de papel.

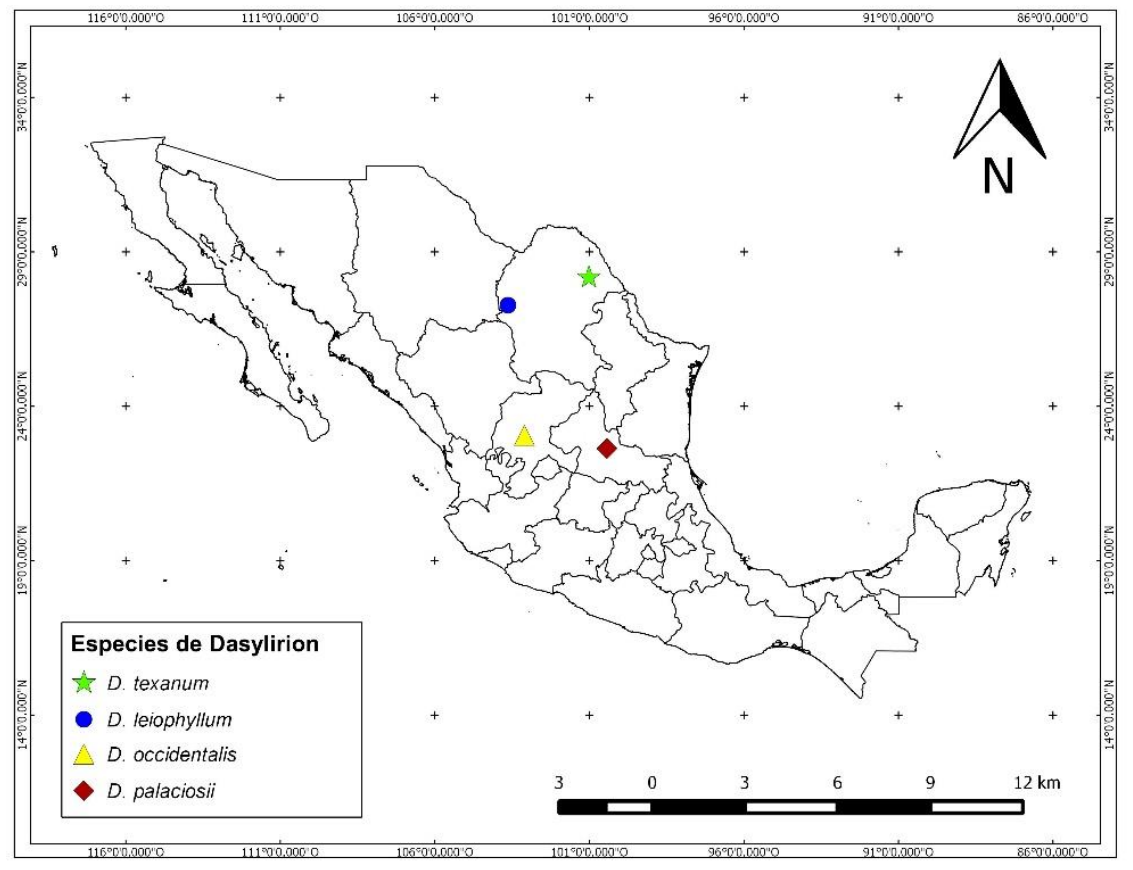

Figura 1. Sitios de colecta de material vegetal de especies de Dasylirion. Las localidades comprenden los estados de Coahuila, Zacatecas y San Luis Potosí.

\section{Extracción de DNA}

Para obtener el DNA de las diferentes especies, se utilizó la metodología de Lopes et al. (1995) modificada. Se colocaron $20 \mathrm{mg}$ de tejido fresco en un mortero estéril y se molieron con $\mathrm{N}_{2}$ líquido, el polvo resultante se colocó en un tubo eppendorf de $2 \mathrm{~mL}$ y se agregaron $800 \mu \mathrm{L}$ de buffer de lisis (Tris- $\mathrm{HCl} 100 \mathrm{mM}$ a pH= 8, $\mathrm{NaCl} 20 \mathrm{mM}$, EDTA $20 \mathrm{mM} \mathrm{pH=8}$ y N-Lauril-sarcosina al 1\%), se mezcló completamente y se dejó reposar por $10 \mathrm{~min}$. Se agregaron $800 \mu \mathrm{L}$ de fenol (Sigma, Phenol Solution, equilibrado con Tris HCL $10 \mathrm{mM}$, pH 8, EDTA1 mM) para biología molecular, se agitó en un vortex y se centrifugó por $20 \mathrm{~min}$ a $4{ }^{\circ} \mathrm{C}$ a $12000 \mathrm{rpm}$.

Se recuperó la fase acuosa en un nuevo tubo eppendorf y se agregaron $100 \mu \mathrm{L}$ de RNAsa en concentración de $10 \mathrm{mg} \mathrm{mL}^{-1}$ y se mezcló por inversión. Se agregaron $800 \mu \mathrm{L}$ de isopropanol frío $\left(-20{ }^{\circ} \mathrm{C}\right)$, se mezcló hasta formar la madeja de DNA, la cual se colectó con un gancho de pipeta Pasteur estéril y se trasfirió a un tubo nuevo eppendorf de $1.5 \mathrm{~mL}$. La pastilla se lavó con $200 \mu \mathrm{L}$ de alcohol al $70 \%\left(-20^{\circ} \mathrm{C}\right)$ y se decantó. Se dejó secar por 15 min y se resuspendió en agua destilada estéril, donde se mantuvo en refrigeración a $-20{ }^{\circ} \mathrm{C}$. Para su visualización se corrió un gel de agarosa al 1\%, con adición del colorante GelRed Nucleid Acid Biotum, en proporción de $1 \mu \mathrm{L}$ por cada $10 \mathrm{~mL}$ de gel. Las muestras de DNA obtenidas se cuantificaron por medio de NanoDrop ND-1 000 (Software ND-1000) y a partir de las lecturas se prepararon diluciones de DNA a $50 \mathrm{ng} \mu \mathrm{L}^{-1}$ en agua estéril. 


\section{Amplificación con nuevos iniciadores}

Para probar la eficiencia de los nuevos iniciadores se realizó el proceso de amplificación para cada especie de Dasylirion. La reacción en cadena de la polimerasa (PCR) se llevó al cabo en un volumen de $50 \mu \mathrm{L}$. Cada reacción contenía $5 \mu \mathrm{L}$ de Buffer Taq Standard 10X, $1 \mu \mathrm{L}$ de dNTPs 10 $\mathrm{mM}, 1 \mu \mathrm{L}$ de iniciador Forward $10 \mu \mathrm{M}, 1 \mu \mathrm{L}$ de iniciador Reverse $10 \mu \mathrm{M}, 0.25 \mu \mathrm{L}$ de Taq polimerasa, $37.75 \mu \mathrm{L}$ de agua libre de nucleasas y $4 \mu \mathrm{L}$ de DNA templado (dilución $50 \mathrm{ng} \mu \mathrm{L}^{-1}$ de DNA en agua estéril) lo anterior, de acuerdo al protocolo de kit BioLabs (Taq DNA Polymerase with Standard Taq Buffer, este último con Mg incluido).

Para obtener una temperatura de alineación (Tm) óptima para los nuevos iniciadores, se corrió una PCR en gradiente de 12 temperaturas diferentes, con la inclusión de las recomendadas por el proveedor $\left(56.7^{\circ} \mathrm{C}\right.$ matK $335 \mathrm{~F}$ y $57.7^{\circ} \mathrm{C}$ matK $\left.1327 \mathrm{R}\right)$. La mejor respuesta se obtuvo con la temperatura de $57.8^{\circ} \mathrm{C}$. A partir, de este resultado se realizó una PCR de punto final de 40 ciclos, con tres temperaturas diferentes: fase de desnaturalización inicial $94{ }^{\circ} \mathrm{C}$ por $4 \mathrm{~min}$, fase de desnaturalización $94{ }^{\circ} \mathrm{C}$ por $30 \mathrm{~s}$, fase de hibridación $57.8^{\circ} \mathrm{C}$ por $35 \mathrm{~s}$, fase de extensión $72{ }^{\circ} \mathrm{C}$ por $35 \mathrm{~s}$ y fase de extensión final $72{ }^{\circ} \mathrm{C}$ por $10 \mathrm{~min}$.

Este procedimiento se llevó a cabo en un termociclador Axigen Maxigene. Para visualizar los productos de PCR, se corrió una electroforesis en gel de agarosa al 1\% (para cada especie), con el uso del buffer TBE 0.5 X, adicionado con el colorante GelRed Nucleid Acid Biotum en proporción de $1 \mu \mathrm{L}$ por cada $10 \mathrm{~mL}$ de gel. Para cargar las muestras, se mezclaron $5 \mu \mathrm{L}$ de producto de PCR con $3 \mu \mathrm{L}$ de buffer de carga (Track $\mathrm{It}^{\mathrm{TM}}$ Cyan/Orange Loading Buffer). Como marcador de peso molecular se utilizó $1 \mathrm{~Kb}$ Plus DNA Ladder - Life Technologies. La electroforesis se corrió en una cámara horizontal a 115 Volts durante $30 \mathrm{~min}$. El gel se observó en fotodocumentador Enduro TM GDS de la marca Labnet International, Inc.

\section{Secuenciación}

Como una prueba más de la calidad de los amplicones obtenidos y para analizar si funcionan para el enfoque de código de barras, se secuenciaron los productos de PCR de D. texanum, en el Laboratorio de Servicios Genómicos (LabSerGen) de la Unidad de Genómica AvanzadaCINVESTAV, Irapuato, Guanajuato. Se utilizó un secuenciador 3 730xl DNA Analyzer (Applied Biosystems) y la secuenciación se hizo en los dos sentidos.

\section{Calidad de secuencias nucleotídicas}

Las secuencias obtenidas a partir de la amplificación con los nuevos iniciadores (matK 335F y matK $1327 \mathrm{R}$ ) fueron evaluadas, a través de sus electroferogramas con el programa Finch TV versión 1.4.0. El programa proporciona un valor de calidad denominado 'valor de calidad Q'. Este valor calculado como el logaritmo base 10 de la probabilidad de error multiplicado por -10, es la factibilidad de identificar una base nitrogenada en una posición específica dentro de una secuencia.

De esta manera valores de $\mathrm{Q}=10(\mathrm{Q} 10)$, representan la probabilidad de error de uno en diez (1/10), $\mathrm{Q}=20(\mathrm{Q} 20)$, probabilidad de error de uno en cien $(1 / 100), \mathrm{Q}=30(\mathrm{Q} 30)$, probabilidad de error de uno en mil (1/1 000) y Q= 40 (Q40) la probabilidad de error de uno en 10000 (1/10 000). Secuencias con valores promedio de $\mathrm{Q}=30$ o mayores, se consideran de buena calidad (NABR, 2012). 


\section{Resultados y discusión}

\section{Evaluación de los iniciadores matK 390F y matK $1326 \mathrm{R}$}

La obtención de un proceso de amplificación o PCR exitoso, depende de un considerable número de variables, entre ellas están las condiciones del aparato donde se lleva a cabo la reacción y la funcionalidad de los reactivos implicados en la reacción misma. Si el proceso falla, se pueden realizar ciertas modificaciones a la técnica, que ayuden a hacer más eficiente el proceso (EspinosaAsuar, 2007). Entre las variables que se revisaron para probar la amplificación de los iniciadores matK 390F y matK $1326 \mathrm{R}$ se encuentra la calidad del DNA utilizado, con valores de relación de absorbancia $260 / 280=1.6$ a 1.8 , indicativo de buena calidad (baja cantidad de proteínas).

Se renovaron los reactivos para PCR (dNTPs, Taq polimerasa, agua ultra pura, buffer con y sin $\mathrm{Mg}$ ), descartando posibles fuentes de contaminación y se probaron variantes en las concentraciones de cada reactivo. Los tubos, puntillas y contenedores, fueron esterilizados en autoclave, la campana de flujo laminar fue desinfectada y los productos obtenidos se visualizaron en gel de agarosa.

En la Figura 2 se presentan cuatro patrones electroforéticos. Cada uno muestra los productos de PCR a partir de los iniciadores matK 390F y matK $1326 \mathrm{R}$ (Cuénoud et al., 2002) para cada especie de Dasylirion. Las Figuras 2a y 2b, corresponden a las especies $D$. palaciosii y D. texanum, respectivamente. En ambas imágenes se muestran la ausencia de bandas amplificadas, excepto en el caso de los controles positivos $(\mathrm{C}+)$ que corresponden a D. micropterum, cuya secuencia registrada en el GenBank (Reyes-Valdés et al., 2016, KU535883.1) fue obtenida, a partir de los iniciadores $m a t K$ 390F y matK $1326 \mathrm{R}$, donde la presencia de amplicón es evidente.

Las Figuras 2c y 2d corresponden a las especies $D$. occidentalis y D. leiophyllum. Se aprecian bandas con mayor definición, sobre todo en la especie $D$. occidentalis, donde se lograron amplificar muestras de siete ejemplares. Sin embargo, en D. leiophyllum el bandeo es intermitente y muestra bandas débiles y marcadas de forma alternada.

a)

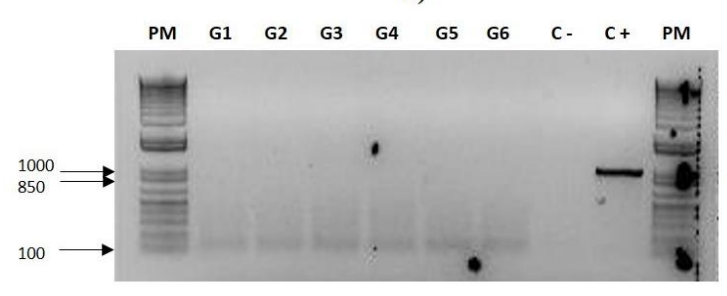

c)

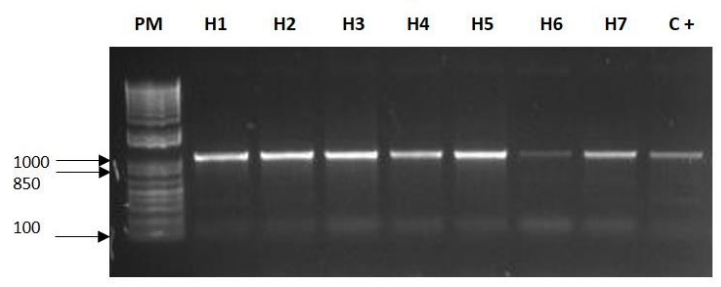

b)

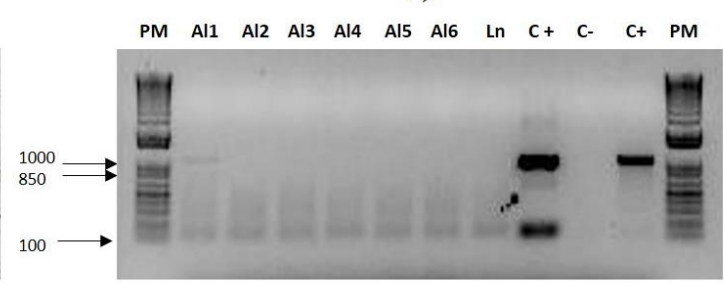

d)

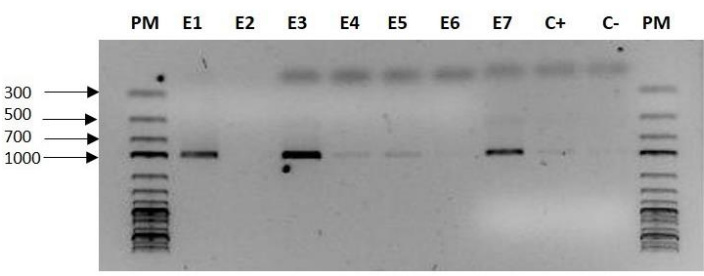

Figura 2. Resultados de PCR de una secuencia parcial del gen $m a t K$ a partir del par de iniciadores matK 390F y matK 1 326R (Cuénoud et al., 2002) en especies del género Dasylirion. a) $D$. palaciosii; b) D. texanum; c) D. occidentalis; y d) D. leiophyllum. 
Las bandas obtenidas en los diferentes geles (Figura 2), correspondientes a D. micropterum como control positivo $(\mathrm{C}+)$, son evidencia de que los iniciadores matK 390F y matK $1326 \mathrm{R}$ no se encuentran degradados y son efectivos para dicha especie. Mientras que la presencia de bandas intermitentes, aunado a la obtención de secuencias de mala calidad con valores promedio de $\mathrm{Q}<$ 30 , son prueba de que los iniciadores no son efectivos en las especies restantes.

Para llevar al cabo un proceso efectivo de PCR, es necesario que uno de los iniciadores tenga la misma secuencia que se encuentra en una de las cadenas del DNA y el otro iniciador tenga la secuencia complementaria que estará al final del fragmento que se quiere amplificar, si esto no es así, no podrá amplificarse efectivamente el sitio seleccionado (Espinosa-Asuar, 2007).

El gen matK es una de las secuencias codificantes de evolución más rápida del genoma plástido. Sin embargo, presenta bajas tasas de amplificación y secuenciación debido a la baja universalidad de los iniciadores (Hilu y Liang, 1997; Hollingsworth et al., 2011; Jing et al., 2011). Esta característica puede ser la causa principal de la ausencia de bandas, el bandeo débil y la presencia de bandas secundarias (Figura 2b y Figura 2d) en la amplificación con los iniciadores universales de las diferentes especies de Dasylirion.

\section{Análisis de complementariedad}

La Figura 3 presenta los resultados del análisis de complementariedad entre el oligonucleótido matK $390 \mathrm{~F}$ y las secuencias de $D$. wheeleri y $D$. serratifolium por medio de alineación con BLASTn. Se encontró que existe diferencia de dos bases nitrogenadas por comparación. El iniciador matK 390F al momento de alinearse con las secuencias completas de Dasyliron difieren con la posición 405 que corresponde a una Adenina (A) y con la posición 417 que corresponde a una Timina (T). El iniciador reverso (matK $1326 \mathrm{R}$ ) presentó complementariedad completa. A la falta de alineación entre bases nitrogenadas del iniciador matK $390 \mathrm{~F}$, se atribuye la falla en el proceso de amplificación del gen matK en las especies de Dasylirion.

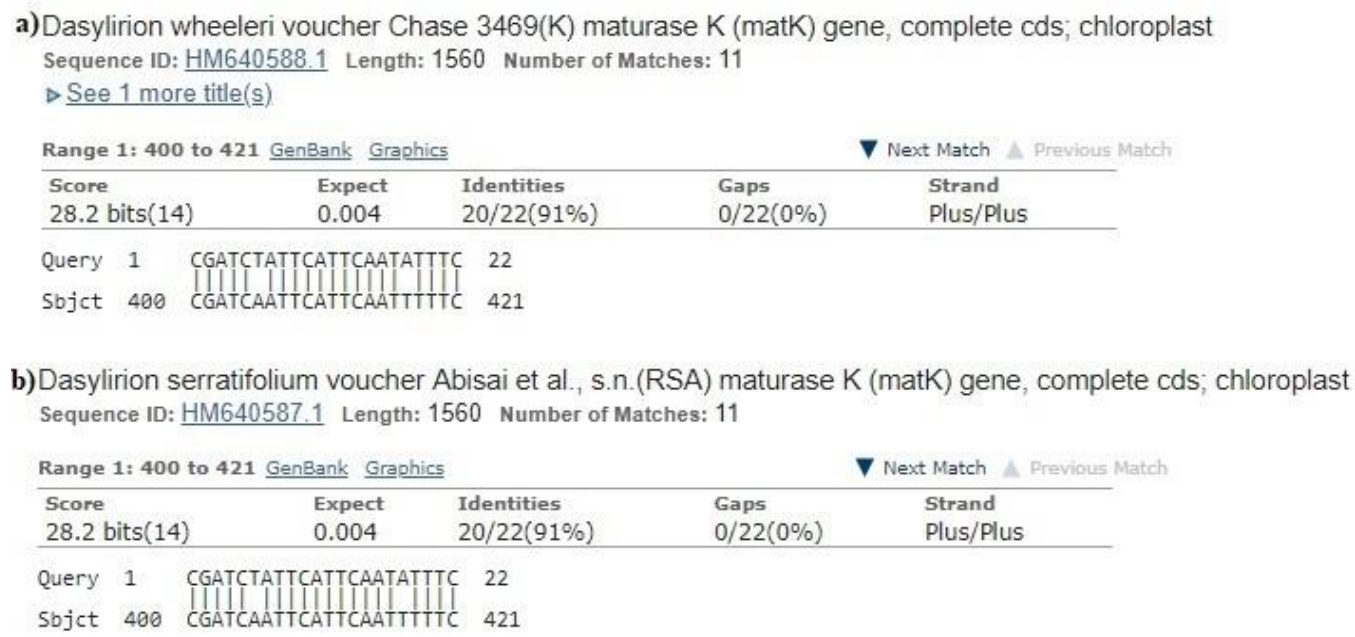

Figura 3. a) Alineación del iniciador matK 390F con respecto a la secuencia del gen completo matK de la especie $D$. wheeleri registrada en GenBank-NCBI; y b) Alineación del iniciador matK $390 F$ con respecto a la secuencia del gen completo matK de la especie $D$. serratifolium registrada en el GenBank. 


\section{Nuevos iniciadores matK}

En el Cuadro 1, se muestran los dos pares de iniciadores diseñados para la amplificación del gen $m a t K$ en especies de Dasylirion. Se eligieron los pares con valores altos de complexidad lingüística y eficiencia en PCR in silico (Kalendar et al., 2017). Ambos pares fueron sintetizados por Eurofins Genomics en concentraciones de $100 \mu \mathrm{M}$.

Cuadro 1. Iniciadores matK generados y probados en FastPCR.

\begin{tabular}{llcc}
\hline \multirow{2}{*}{ Iniciador } & Secuencia (5'-3') & Complejidad lingüística & Eficiencia PCR in silico \\
\cline { 3 - 4 } & & & $(\%)$ \\
\hline matK 335F & tttcattctcgttgcgattag & 85 & 80 \\
matK 1327R & actttattcgatacaaaccctgtt & 93 & 80 \\
matK 413F & caatttttccctttttagaggaca & 79 & 81 \\
matK 1409R & gaacccaatcttcgcaaaa & 71 & 79 \\
\hline
\end{tabular}

\section{Amplificación con nuevos iniciadores matK}

Los pares de iniciadores propuestos (Cuadro 1) se probaron en la amplificación de los fragmentos $m a t K$ para las especies de Dasylirion. El par con menos complejidad lingüística, matK 413F y matK 1 409R, no produjo bandas de amplificación para las especies de Dasylirion. El par matK 335F y $m a t K 1327 \mathrm{R}$ dio resultados satisfactorios en la amplificación del gen mat $K$ en las cuatro especies, con bandas bien definidas en la posición aproximada de 1000 pb (Marcador de PM de $1 \mathrm{~Kb}$ ) y sin presencia de bandas secundarias (Figura 4).
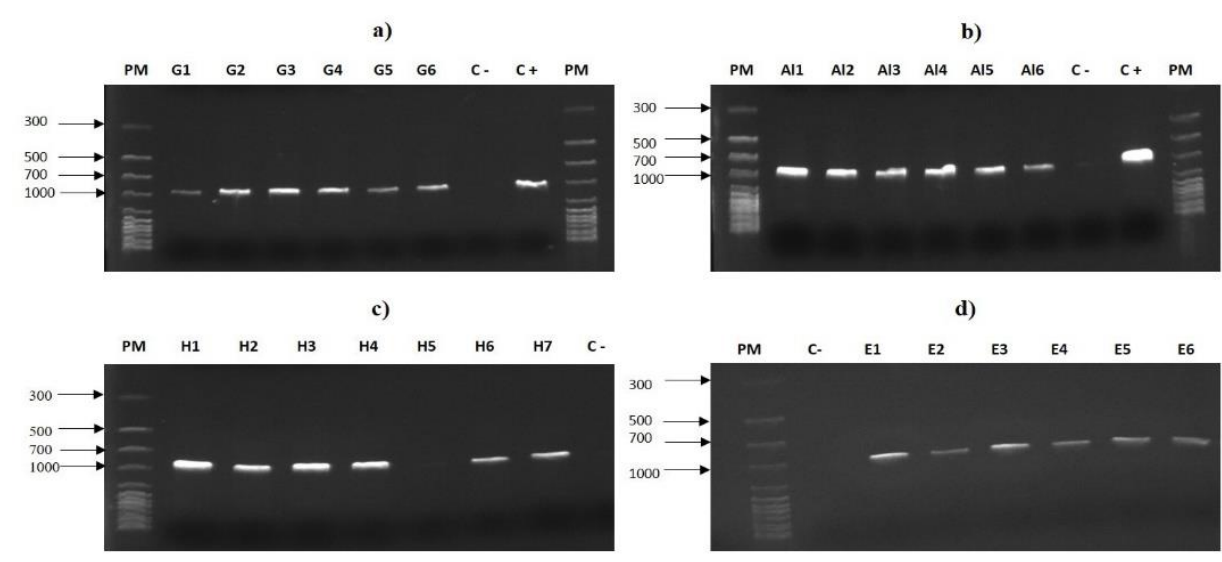

d)

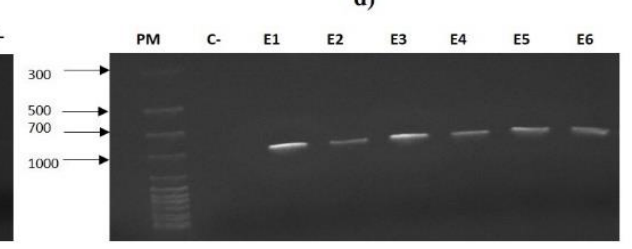

Figura 4. Resultados de PCR de una secuencia parcial del gen matK a partir del par de iniciadores diseñados matK 335F y matK $1327 \mathrm{R}$ en especies del género Dasylirion. a) D. palaciosii; b) D. texanum; c) D. occidentalis; y d) D. leiophyllum.

\section{Secuenciación}

Las secuencias obtenidas de los amplicones de $D$. texanum mostraron ser de buena calidad. Los valores promedio de calidad (Q) fluctuaron entre 36 y 64, por lo cual se consideraron aptos para código de barras de la vida (Jing et al., 2011; NABR, 2012). Las secuencias fueron uniformes entre 
sí. La alineación de la secuencia Al-01 de D. texanum con secuencias matK del grupo Dasylirion (taxid: 39504, GenBank-NCBI), mostró que se puede discriminar de las cuatro especies registradas (Cuadro 2).

Cuadro 2. Substituciones nucleotídicas entre la secuencia Al-01 (D. texanum) con respecto a las secuencias matK de especies de Dasylirion registradas en GenBank.

\begin{tabular}{ccc}
\hline Especie & Registro GenBank & Núm. de substituciones \\
\hline D. miquihuanense & KU535884.1 & 1 \\
D. serratifolium & HM640587.1 & 1 \\
D. serratifolium & AB029800.1 & 1 \\
D. wheeleri & HM640588.1 & 2 \\
D. micropterum & KU535883.1 & 3 \\
\hline
\end{tabular}

La secuencia de D. texanum (Al-01) presentó $99 \%$ de identidad con respecto a las secuencias del grupo Dasylirion, con diferencias de 1 a 3 substituciones nucleotídicas entre especies por comparación: una substitución con respecto a D. miquihuanense (Reyes-Valdés et al., 2016) y D. serratifolium (Tamura, 1999; Kim y Kim, 2010), dos substituciones con respecto a $D$. wheeleri (Kim y Kim, 2010) y tres substituciones con D. micropterum (Reyes-Valdés et al., 2016). El alto porcentaje de identidad entre la secuencia problema y las de referencia del GenBank, así como el número de substituciones nucleotídicas encontradas por alineación, ilustran el valor de los iniciadores $m a t K 335 \mathrm{~F}$ y $m a t K 1327 \mathrm{R}$, para código de barras de la vida con $m a t K$ en Dasylirion.

\section{Conclusiones}

La diferencia de dos bases nitrogenadas en uno de los iniciadores universales (matK 390F) con respecto a la secuencia del gen completo matK de D. wheeleri (GenBank), es la causa atribuible en la falla del proceso de amplificación del gen matK en las especies de Dasylirion en estudio. Los iniciadores matK 335F y matK $1327 \mathrm{R}$ diseñados en esta investigación, permitieron la amplificación de fragmentos cercanos a $1000 \mathrm{pb}$ en todas las especies estudiadas de Dasylirion (D. occidentalis, D. palaciosii, D. texanum, D. leiophyllum).

Las secuencias obtenidas, de cada especie de Dasylirion, presentaron valores promedios de $\mathrm{Q}$ de entre 36 y 64, con lo cual se consideran fragmentos de calidad suficiente para obtener código de barras de la vida. Las secuencias de D. texanum fueron uniformes entre sí y con variación en la substitución nucleotídica con respecto a las secuencias matK (género Dasylirion) registradas en el GenBank. Los resultados indican que los nuevos oligonucleótidos ( $m a t K 335 \mathrm{~F}$ y $m a t K 1327 \mathrm{R}$ ) son de valor para la obtención de código de barras de la vida en especies del género Dasylirion. En particular, las cuatro especies con referencia en el GenBank y $D$. texanum, estudiada en el presente trabajo, pueden ser diferenciadas entre sí con la secuencia parcial del gen matK. 


\section{Agradecimientos}

A la Universidad Autónoma Agraria Antonio Narro por el apoyo financiero para el desarrollo de este proyecto. A la Unidad de Genómica Avanzada-CINVESTAV, Irapuato, Guanajuato, por las facilidades en la realización de este proyecto. Al Consejo Nacional de Ciencia y Tecnología (CONACYT) por su apoyo a través de una beca de doctorado.

\section{Literatura citada}

Bogler, D. J. 1994. Taxonomy and phylogeny of Dasylirion (Nolinaceae). Ph. D. Dissertation, Faculty of The University of Texas, Austin, Texas. 583 p.

Bogler, D. J. 1998. Three new species of Dasylirion (Nolinaceae) from Mexico and a clarification of the D. longissimum complex. Brittonia. 50(1):71-86.

CBOL. 2009. Plant Working Group. A DNA barcode for land plants. Proc. Natl. Acad. Sci. USA. 106(31):12794-12797.

Cuénoud, P.; Savolainen V.; Chatrou, L. W.; Powell, M.; Grayer, R. J. and Chase, M. W. 2002. Molecular phylogenetics of caryophyllales based on nuclear $18 \mathrm{~S}$ rDNA and plastid rbcL, atpB, and matK DNA sequences. Am. J. Bot. 89(1):132-144.

Encina, D. J. A.; Meave, J. A. and Zárate, L. A. 2013. Structure and woody species diversity of the Dasylirion cedrosanum (Nolinaceae) rosette scrub of central and southern Coahuila State, Mexico. Bot. Sci. 91(3):335-347.

Espinosa, A. L. 2007. Guía práctica sobre la técnica de pcr. In: ecología molecular. Eguiarte L. E.; Souza, V. y Aguirre, X. (Comp.). Instituto Nacional de Ecología (INE)-Secretaría de Medio Ambiente y Recursos Naturales (SEMARNAT). México, DF. 517-536 pp.

González, M. F. 2012. Las zonas áridas y semiáridas de México y su vegetación. Secretaría de Medio Ambiente Recursos Naturales (SEMARNAT)-Instituto Nacional de Ecología (INE). $1^{\mathrm{a}}$. (Ed.). México. $194 \mathrm{p}$.

Granados, S. D.; Sánchez, G. A.; Granados, V. R. L. y Borja de la Rosa, A. 2011. Ecología de la vegetación del desierto chihuahuense. Rev. Chapingo Ser. Cienc. Forest. Amb. Edición especial. 17:111-130.

Hausner, G.; Olson, R.; Simon, D.; Johnson, I.; Sanders, E. R.; Karol, K. G.; McCourt, R. M. and Zimmerly, S. 2006. Origin and evolution of the chloroplast $\operatorname{trnK}(\mathrm{mat} K)$ intron: a model for evolution of group II intron RNA structures. Mol. Biol. Evol. 23(2):380-391.

Hebert, P. D.; Cywinska, A.; Ball, S. L. and de Waard, J. R. 2003. Biological identifications through DNA barcodes. Proceedings Biological Sciences. 270(1512):313-321.

Hilu, K. W. and Liang, H. 1997. The $m a t K$ gene: sequence variation and application in plant systematics. Am. J. Bot. 84(6):830-839.

Hollingsworth, P. M.; Graham, S. W. and Little, D. P. 2011. Choosing and using a plant DNA barcode. PLoS One. 6(5):e19254.

IMPI. 2002. Instituto Mexicano de la Propiedad Industrial. Declaración de protección a la denominación de origen sotol. http://www.dof.gob.mx.

Jing, Y.; Jian-Hua, X. and Shi-Liang, Z. 2011. New universal matK primers for DNA barcoding angiosperms. Journal of Systematics and Evolution. 49(3):176-181.

Kalendar, R.; Khassenov, B.; Ramankulov, Y.; Samuilova, O. and Ivanov, K. I. 2017. FastPCR: an in silico tool for fast primer and probe design and advanced sequence analysis. Genomics. 109(4-5):312-319. 
Kim, D. K. and Kim, J. H. 2010. National center for biotechnology information. Life sciences. Kyungwon University, 65 Bokjeong-Dong, Sujeong-Gu, Seongnam-Si, Gyeonggi- Do 461-701. Korea. https://www.ncbi.nlm.nih.gov/.

Lopes, M. A.; Takasaki, K.; Bostwick, D. E.; Helentjaris, T. and Larkins, B. A. 1995. Identification of two opaque 2 modifier loci in quality protein maize. Molecular and General Genetics. 247(5):603-613.

NABR. 2012. Northwest Association for Biomedical Research. Analyzing DNA sequences and DNA barcoding: using bioinformatics for genetic research. 281-318 pp.

Reyes, V. M. H.; Benavides, M. A.; Ramírez, R. H. y Villarreal, Q. J. A. 2012. Biología e importancia del sotol (Dasylirion spp.) Parte I: sistemática, genética y reproducción. Planta. 7(14):11-13.

Reyes, V. M. H.; Martínez, O. and Hernández, G. F. 2016. National center for biotechnology information. Plant Breeding. Universidad Autónoma Agraria Antonio Narro, Calzada Antonio Narro 1923, Saltillo, Coahuila 25315, México._https://www.ncbi.nlm.nih.gov/.

Roy, S.; Tyagi, A.; Shukla, V.; Kumar, A.; Singh, U. M.; Chaudhary, L. B.; Datt, B.; Bag, S.K.; Singh, P. K.; Nair, N. K.; Husain, T. and Tuli, R. 2010. Universal plant DNA barcode loci may not work in complex groups: a case study with Indian Berberis species. PLoS One. 5(10):e13674.

Rozen, S. and Skaletsky, H. J. 2000. Primer 3 on the www for general users and for biologist programmers. In: Misener, S. and Krawetz, S. A. (Eds.) Bioinformatics methods and protocols: methods in molecular biology. Humana Press, Totowa, NJ, USA. 365-386 pp.

Rzedowski, J. 1965. Relaciones geográficas y posibles orígenes de la flora de México. Bol. Soc, Bot. Méx. 29: 121-177.

Sarukhán, J.; Koleff, P.; Carabias, J.; Soberón, J.; Dirzo, R.; Llorente-Bousquets, J.; Halffter, G.; González, R.; March, I.; Mohar, A.; Anta, S. y de la Maza, J. 2009. Capital natural de México. Síntesis: conocimiento actual, evaluación y perspectivas de sustentabilidad. Comisión Nacional para el Conocimiento y Uso de la Biodiversidad (CONABIO). México. $104 \mathrm{p}$.

Short, L.; Thoms, A. V.; Cao, B.; Sinyukov, A. M.; Joshi, A.; Scully, R.; Sanders, V. and Voronine, D. V. 2015. Facile residue analysis of recent and prehistoric cook stones using handheld Raman spectrometry. J. Raman Spectroscopy. 46(1):126-132.

Tamura, M. N. 1999. National center for biotechnology information. Department of botany. Graduate School of Science, Kyoto University; Kitashirakawa-oiwake-cho, Sakyo-ku, Kyoto 606-8502, Japan. https://www.ncbi.nlm.nih.gov/.

The Plant List. 2013. Version 1.1. Published on the Internet. http://www.theplantlist.org.

Tropicos. org. 2018. Missouri botanical garden. http://www.tropicos.org/Name/40022176.

Villarreal, Q. J. A.; Estrada, C. E.; Reyes, V. M. H.; Encina, D. J. A.; Martínez, O. and Hernández, G. F. 2016. Dasylirion micropterum (Asparagaceae), a new species from Sierra Madre Oriental, Mexico. Phytotaxa. 253(2):139-146.

Villaseñor, J. L. 2016. Checklist of the native vascular plants of Mexico. Catálogo de las plantas vasculares nativas de México. Rev. Mex. Biod. 87(3):559-902. 